\title{
Youth exchange programs in the SCO countries and their integrative potential: Russia's vantage point
}

\author{
Svetlana Maximova ${ }^{1}$, Daria Omelchenko ${ }^{1,{ }^{*}}$, Oksana Noyanzina $^{1}$, and Maksim Maksimov ${ }^{1}$ \\ ${ }^{1}$ Altai State University, Department of Psychology of Communications and Psychotechnologies, \\ 656049, 61 Lenin ave., Barnaul, Russia
}

\begin{abstract}
In today's world international cooperation is the basis for sustained economic growth and development, allowing overcoming imbalances and improving the quality of life, renovating technologies and knowledge, achieving other goals of the millennium development. The importance of studying perspective of development of youth exchanges in countries members of the SCO is determined by its role in strengthening mutual trust and good neighbourly relations; development of the integration process in the fields of education, science and technologies; giving new impetus to enhancement of multilateral cooperation. The purpose of this article is to present the analysis of youth exchanges among Russia, China, Kazakhstan, Kyrgyzstan, Tajikistan and Uzbekistan based on the results of sociological survey among participants of international exchange programs $(n=449)$. It was found that young people are more interested in cultural programs and programs aimed at developing youth policy rather than educational and academic programs. Expectations and intentions of youth from the SCO countries are often linked to Russia, most respondents have plans to participate in youth exchanges in this country. The research led to findings about factors of development of youth exchanges within the SCO, that could be used for correction of strategies, choice of methods and forms of work, more effective decisionmaking in the field of youth policy, forecasts about potential of the development of the SCO youth organization.
\end{abstract}

\section{Introduction}

One of distinctive features of international relations in XXI century is facilitating communication among different groups of people, particularly young, specialists in humanitarian and other spheres of human activity. Every year, millions of people participate in different exchange programs, including scientific stages, conferences, workshops, different learning activities, that contributes to the development of cultural and economic relations between states, the general scientific and technical progress, improving global civilization.

\footnotetext{
* Corresponding author: daria.omelchenko@mail.ru
} 
The notion of exchange programs is not limited to science and education, within the diversity of programs several categories can be identified: sociocultural programs, which main objectives are to get acquaintance with life in the country, learning foreign language, history, traditions and customs, debunking ethnic and national stereotypes and preconceptions; educational and scientific programs, aimed at receiving formal professional education and conducting scientific research, including preparation of master and doctoral dissertations; professional internships, directed at receiving practical skills and useful for undergraduates and young specialists wanting to extend their knowledge and gain experience. Another category - programs, undertaken in the framework of bilateral and multilateral agreements in the field of youth policy and youth work. Such programs involve socially active youth having leadership potential, able not only to learn, but also to carry out different practically-oriented projects. Different kinds of exchange programs require various institutional and legal mechanisms and practices, conceptualized in the context of different fundamental and applied research fronts. Important theoretical grounds on which we have relied in our research were focused on concepts of international education and academic mobility [1], spatial mobility and life transitions [2], public diplomacy and soft power [3,4].

Nowadays, integration of Russia into global community, especially into international educational area, is evident: the country is actively involved into globalization and internalization of science and education, its humanitarian contacts are enlarging, that is among others due to reforms and transformations of the last decade. Russia becomes more open for external contacts and communication not only at the level of state agencies and institutions, but also for ordinary citizens, including pupils, students, young specialists [5, 6]. In Russian higher school integrative movement is mainly observed in European direction, Asian vector is promising but rather recent. Educational programs and activities, elaborated by governmental agencies for the realization of foreign-policy goals are financed from the budget and represent significant part of international exchanges, there are programs of cultural exchange, youth programs of seasonal employment, voluntary movement and other forms of international activity, engaging young people [7].

General preconditions for development of international academic cooperation and exchange programs following the official accession to the Bologna process are integration processes in the field of economics, including increase in territorial mobility of labor force, engendering necessity in identification and recognition of documents about education, professional qualification, received in different countries, high diversity in educational area $[8,9]$. Academic mobility and other forms of youth exchanges are effective instruments of improving quality of human capital, enhancing competitiveness of national educational systems [10]. Participation in foreign research activities, internships and practices contributes to a deeper learning of disciplines, increase motivation for scientific and innovative activity, develop personal qualities such as responsibility, analytical thinking, initiative, adaptivity, stress management, flexibility and decision-making, cross-cultural professional communication skills [11].

One of the biggest and dynamically developing multifaceted and multidimensional associations among Asian countries with which Russia connects its future socio-economic, political and socio-cultural future is the Shanghai Cooperation Organization (SCO), created in 2001 by leaders from China, Russia, Kazakhstan, Tajikistan, Kyrgyzstan and Uzbekistan $[12,13]$. The place and the role of the SCO in the system of global international relations is defined by its scope, peculiarities of organizational structure and principles of activity. The total area of member countries of the SCO comprises $60 \%$ of the Eurasian territory (30 million square), and overall demographic potential - over 1.5 billion people, that is almost a quarter of global population. The establishment of SCO is strong evidence for possibility of multipolar global governance at the regional level and building democratic international 
relations on the basis of so called corporate approach and "Shanghai spirit", taking into account the interests of all parties, so that peace and stability diversity of cultures and traditions can prevail in that region. The states, united into the SCO, relate to each other by common history and geographic position, visions and values, they are concerned about same issues. The Russian Federation in its foreign policy give a special place to "further strengthening of the SCO, promoting its initiatives on creation of networks of partner communication among all integration entities in the Asian-Pacific region" (Foreign policy concepts of the Russian Federation, 2008). Institute of international youth cooperation play a great role in these initiatives. The rich international experience has already proved the efficacy of exchange programs in resolving the tasks of youth development, formation of human capacity and young leadership. There is a need for detailed research and scientific reflection to be carried out regarding the SCO experience in international cooperation in the framework of international exchange programs, to assess opportunities and prospects for collaboration, problems and restrictions. The purpose of this article is to present results of the research, focused on the assessment of the actual state and perspectives of development of youth exchanges among member countries of the SCO, especially among Russia, China, Kazakhstan, Kyrgyzstan, Tajikistan and Uzbekistan.

\section{Methods}

Within the framework of the scientific research in countries members of the SCO a survey with participants of international youth exchange programs was conducted in 2014-2015 $(\mathrm{n}=449)$. The sample has been designed to select respondents among young people who recently participated in programs of youth exchanges in the SCO countries. The survey has covered youngsters, taking part in activities, organized with the support of the Ministry of Education and Science of the Russian Federation, Federal Agency on Youth Affairs, Federal Agency for the Commonwealth of Independent States Affairs, Compatriots Living Abroad and International Humanitarian Cooperation (Rossotrudichestvo), Association of Asian universities.

The analysis of current situation and perspectives of the development of youth exchanges among countries members of the SCO (Russia, China, Kazakhstan, Kyrgyzstan, Tajikistan, Uzbekistan) has taken into account the differentiation of participation of youth in SCO exchange programs, especially during Russia's SCO Presidency in 2014-2015, different kinds of programs, sources of information on exchange programs and motivation.

The assessment of the level of satisfaction with different aspects of youth exchange programs as a principal determinant of their integrative potential has been carried out using 10-point scales, analyzed by means of descriptive and multivariate statistical instruments ( $\mathrm{t}$ tests, one-way ANOVA, regression models).

The study involved participants from Russia (21.2\%), China (22,3\%), Kazakhstan $(15,6 \%)$, Tajikistan $(15,6 \%)$, Kyrgyzstan $(14,7 \%)$. Citizens of other countries, including Uzbekistan, represented $10.7 \%$. Mean age of participants - 22 years, gender distribution $48.5 \%$ of males and $51.5 \%$ of females. Almost a half of respondents (49\%) had higher education, $35.7 \%$ - uncompleted higher education, $14.4 \%$ - secondary vocational education. The majority of youth exchange programs participants $(84 \%)$ represented higher education institutions - institutes, universities or academies, less than $10 \%$ of respondents were representatives of secondary education system (schools, lyceums, gymnasiums), public youth organizations were represented by $3.8 \%$ of respondents, institutions of secondary vocational education (colleges, technical schools) - by $2 \%$ of respondents. 


\section{Results}

\subsection{Characteristics of international programs of youth cooperation}

The analysis of participation of youth in international programs has shown that most frequently attended were programs, devoted to cultural exchanges and realization of youth policy in the SCO countries $(57.3 \%)$ in comparison with educational and academic exchanges $(42.7 \%)$.

Differentiation of participation of young people by kinds of programs has allowed to present the ranking of these programs according to their frequency distribution:

1. Study in the framework of institution-to-institution agreements during one or more terms without issuance of the second diploma (63.5\%);

2. Joint events for exchanging experiences in the field on youth policy $(37.6 \%)$;

3. Exchanges between educational institutions, including exchanges between pupils, teachers and university staff $(26.2 \%)$;

4. Short-term visits aimed at acquainting and experience exchange (24.8\%);

5. Joint cultural activities involving young creators and new amateur artists $(21,7 \%)$;

6. Collaborative research programs and follow-up conferences (19.0\%);

7. International sport competitions, tourist forums and festivals $(18.3 \%)$;

8. Collaborative activities on social-political, historical, social-economic, ecological and legislative issues (14.3\%);

9. Vocational training and internships (13.4\%);

10. Joint voluntary labor youth summer camps $(13.0 \%)$;

11. Traineeship projects, including language internship programs (10,3\%);

12. Participation in summer schools (terms) $(8.3 \%)$;

13. Organization of joint youth summer camps $(8.1 \%)$;

14. Double degree joint and exchange programs $(5,1 \%)$;

15. Activities aimed at learning and dissemination of the Russian language in the countries-partners $(4.3 \%)$;

16. Collaboration of youth publishing houses and media, exchanges of young journalists $(4.3 \%)$.

All the SCO member countries implement and support international exchange programs. According to the results obtained, the youth more frequently take part in international programs, carried out in Russia (29.7\%), China (17.2\%), Kazakhstan (16.6\%), Tajikistan (13.3\%), and to a lesser extent in Kyrgyzstan (12.0\%), Uzbekistan $(7.0 \%)$ (picture 1).

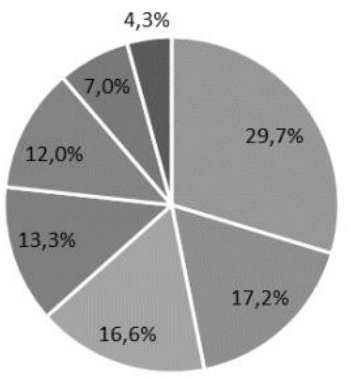

$$
\begin{aligned}
& \text { = Russia }=\text { China }=\text { Kazakhstan }=\text { Tajikistan } \\
& \text { - Kyrgyzstan = Uzbekistan = Other countries }
\end{aligned}
$$

Pic. 1. Participation in international programs in countries members of $\mathrm{SCO}, \%$. 
Three groups of programs could be divided by period of their realization: short-term programs lasting one month or less, mid-term programs of up to six months and long-term programs. Short-term youth exchange programs are usually of introductory nature, they are more often attended by young people from Russia and other countries (non-SCO). The midterm and long-term programs, realized in Russia suppose educational and academic exchanges, requested by young citizens of China, Tajikistan and Kyrgyzstan.

One of the key research questions concerned participation of youth in exchange programs in SCO countries during Russia's Presidency in 2014 - 2015. The study has revealed that among such programs priority was given to educational programs of the University of Shanghai Cooperation Organization (USCO) (48.3\% of answers), a network university, combining educational potential of several universities from Kazakhstan, China, Kyrgyzstan, Russia and Tajikistan. Education at USCO is based on academic exchange during which each student of joint cooperation program must spend at least one term in partner university from another country. These educational programs were especially popular among young people from China (87.8\%) and Tajikistan $(66.7 \%)$, and to a lesser degree from Kazakhstan (45.5\%), Kyrgyzstan (38,5\%) and Russia (19,4\%). Another significant part of exchange programs - cultural internships - involved $34.9 \%$ of active young people from SCO countries. Other activities were less but represented and included scientific and hands-on training (13.6\%), language programs (13.2\%); summer schools $(10,6 \%)$, scientific internships $(7.6 \%)$. Double degree programs were attended by $20 \%$ of respondents, among which $10.2 \%$ - took part in master's degree programs and $9.9 \%$ - in bachelor's degree programs. Interesting trends had been identified in the analysis of comparison of program choice in different countries. Thus, educational and academic exchanges were more attractive for young people from Tajikistan (91.7\%) and Russia (51.4\%), whereas cultural exchanges and programs concerning youth policy - for representatives of Uzbekistan (75.0\%), Kyrgyzstan (71.4\%) and China (70.0\%). Kazakh youth participated equally in both educational and academic exchanges and in exchanges with cultural or youth political purposes.

Information about youth exchange programs is most often provided by youth organizations $(85.7 \%)$, foreign partners, professors and specialist in youth work $(52.3 \%)$. Often information is given in lectures, conferences and seminars $(80.7 \%)$, via Internet and media (71.9\%). Institutionalized forms of information are sought to a much lesser extent, especially resources of the Ministry of education of a country $(25.5 \%)$; regional ministries and departments of educational management $(31,8 \%)$; regional committees on youth affairs (36.5\%). There are some specifics in information use in every SCO country, related to internal policy, development of infrastructure, peculiarities of social relations between the State and young people. Thus, official sources (Ministry of education, regional ministries, departments of educational management, regional committees on youth affairs) were most often used by citizens of Tajikistan $(60.3 \% ; 5.9 \%$ and $4.4 \%$ correspondingly). Russian youth were looking to Internet and mass-media $(30,6 \%)$ as well as to other youth organizations (16.1\%). In China there wasn't a clear differentiation of information sources, although young people have noted that more often information comes from foreign partners $(15.6 \%)$, and is given in lectures, seminars and conferences $(13.5 \%)$, received from Internet and media (14.6\%). In Kazakhstan youth give priority to information from Internet and media $(26.2 \%)$, foreign partners $(18.0 \%)$ and the Ministry of education $(18.0 \%)$. In Kyrgyzstan information is mostly given by foreign partners $(25.5 \%)$, Internet and media $(23.6 \%)$. Therefore, youth tend to use particular, non-official channels for finding information about exchanges, official structures aren't very efficient in informing young people about existing programs, and this factor should be considered in further elaboration of youth exchanges programs within the SCO area. 
The young people have distinctive reasons for participation in one or another program. Personal development opportunities were more often cited among possible explanations $(63,9 \%)$, along with opportunity to study experience of foreign colleagues in the field of youth work in a partner organization $(32,5 \%)$; receive language practice and improve knowledge of foreign language $(31,4 \%)$; receive supplementary education, diploma, certificate, providing benefits in searching for a job $(30,1 \%)$; become acquainted with culture and attractions of country-partner $(26,5 \%)$; enhance cooperation in different fields (social work, youth work, youth policy, education) (24.7\%); share practices of engaging young people in social political activities $(18,2 \%)$. To a lesser extent reasons of participation were related with establishing personal contacts $(10.1 \%)$; realization of joint events $(5.5 \%)$; intentions to move to this country later to take up permanent residence (3.6\%); accessibility (low cost for participation and accommodation) $(2.3 \%)$.

Motives for participation are differentiated between representatives of countries participants of the SCO. Practically all young people which took part in our survey have mentioned about importance of self-development, but other reasons were significantly diverse. Thus, young people from Russia more frequently spoke about opportunity to study experience of foreign colleagues in the domain of youth work (39.7\%), enhance cooperation in different fields (social work, youth work, youth policy and education) (39.7\%); get acquainted with culture and attractions of the country-partner $(31.7 \%)$. Chinese respondents have justified their participation in exchange programs by possibilities to receive language practice and improve the knowledge of foreign language (47.4\%); get acquainted with culture and attractions of the country-partner (29.9\%); and get supplementary education, diploma or certificate when seeking employment (29,9\%). For youth from Kazakhstan the possibility to receive supplementary education was more significant (39.7\%) while linguistic competencies and learning from experience in countrypartner occupied lower places in the motivation rating (25.9\% and $22.4 \%$ correspondingly). In Tajikistan and Kyrgyzstan motivation models were similar: the second place was occupied by the possibility of learning from the experience of foreign colleagues about youth work and youth policy in country-partner (50.0\% of answers) and the third place was given to receiving additional education, giving benefit while looking for a job $(23.5 \%$ and $37.5 \%$ ).

International mobility of youth as indicator of its activity is evidenced by repeated participation in exchange programs. The analysis of earlier experience has shown that $43.3 \%$ of respondents have already had a single experience in participation in exchange programs, $14.5 \%$ - took part in similar events several times. Those who were participating in the program for the first time at the moment of the survey $(16.6 \%)$ already have future plans to participate in such programs. According to the results, the most active, are citizens from Russia (23\%) and Kyrgyzstan (21.8\%) who had multiple experiences in exchange programs, the least mobile were young people from China and Kazakhstan: $40.8 \%$ and $30 \%$ of them took part in exchange programs only once. Despite less experience Chinese youth had higher migration potential, in comparison with other countries $-29.6 \%$ of respondents from this country plan to take part in international exchange program in near future.

\subsection{Models of personal and organizational utility of exchange programs}

Descriptive analysis of central tendencies in scales, assessing the significance of factors, influencing the level of satisfaction from participation in exchange program has demonstrated that most respondents have greatly appreciated the quality of organization of programs in which they took part, all mean values were above 7 points, median of six out of eight indicators was 8,0 points, of two indicators - 9,0 points. Personal utility rate, consisting in possibilities of personal growth and self-development, increase in professional 
skills was among highest (mean value 8.15 points), along with cultural component of a program, allowing to get acquainted with cultural heritage, history, customs and traditions of the receiving country, to plunge into everyday life of its inhabitants, to launch an intercultural dialogue (mean value 8.01). Lowest mean values were found for indicators of social support (7.39 баллов), logically related with financial conditions of the program, as it will be shown further. Therefore, it might be said that participation in an exchange program was firstly guided by possibility to develop important personal and sociocultural competencies, whereas organizational factors were in general less significant.

A key factor in determining variability of evaluations was the country of citizenship of participant of the survey. According to the results of the analysis of variance and post hoc tests, differences in mean values for all indicators in groups of respondents by country were statistically significant (F-criterion, $\mathrm{p}<0.05$ ), except for the variable of social support. Three groups of countries were identified, within which differences were negligible. The first group consisted of citizens from Tajikistan and other countries non-members of the SCO, that gave lowest assessments for all indicators. The second group comprised intermediate evaluations from Russia and China, and the third group was represented by respondents from Kazakhstan and Kyrgyzstan, whose evaluations significantly exceeded other countries.

Taking into consideration that personal utility and benefit for organization were among highest factors, determining level of satisfaction, we conducted a series of regression analysis in order to reveal impacts of different aspects of program realization in overall assessment of individual and organization effectiveness of participation. In models, calculated for separate countries, personal utility and organizational utility were chosen as dependent variables, and other indicators were designated as predictors.

The model of personal utility had relatively good quality of explanation, coefficient of determination was the highest for the model of Russia (adjusted R2=0.69) and the lowest for Kazakhstan model (adjusted R2 $=0.41$ ). Comparative analysis of models has shown that the evaluation of personal utility meant different things for young people coming from different countries and was determined by various sets of indicators. Thus, for participants from Russia, the most significant were organizational components of the program, possibility to receive social and financial help (in the form of scholarships or other benefits) as well as cultural and educational program. For Chinese youth and youth coming from countries non-members of the SCO these factors were also important except financial support. For Kazakh youth the most significant was cultural and educative components, possibility to study historical and cultural traditions, whereas other aspects were not relevant. For participants from Tajikistan and Kyrgyzstan it was important to receive linguistic assistance and documental support (only for Tajikistan) (table 1). Hence, young people define personal efficiency gains from participation in exchange programs in their own way. For countries outside the former Soviet Union among the most prominent are educational and cultural factors, associated with the general quality of program organization. For Russian youth, often having poor material conditions and so unable to participate in exchange program with own funds, financial factor played a crucial role. For Kazakh young people inter-cultural understanding and cooperation was in priority whereas education component was of secondary importance. In general, the youth coming from former Soviet Union countries (usually referred as 'near abroad') were more concerned about legal norms, related to stay in the territory and receiving linguistic assistance. 
Table 1. Regression model of personal utility from participation in the exchange program, $*-\mathrm{p}<0.05, * *-\mathrm{p}<0.01$.

\begin{tabular}{|c|c|c|c|c|c|c|}
\hline $\begin{array}{l}\text { Predictors/Country } \\
\text { of citizenship }\end{array}$ & Russia & China & Kazakhstan & Tajikistan & Kyrgyzstan & Other country \\
\hline $\begin{array}{l}\text { Organization and } \\
\text { conduct of exchange } \\
\text { program (schedule, } \\
\text { technical equipment, } \\
\text { handouts and printed } \\
\text { materials and so on) }\end{array}$ & $\mathbf{0 , 3 3}{ }^{*}$ & $0,27^{*}$ & 0,19 & $0,29^{*}$ & 0,06 & $0,42 *$ \\
\hline $\begin{array}{l}\text { Language assistance } \\
\text { (language courses, } \\
\text { assistance of an } \\
\text { interpreter and so } \\
\text { forth) }\end{array}$ & $-0,04$ & $-0,07$ & 0,15 & $0,29^{*}$ & $0,27^{*}$ & 0,04 \\
\hline $\begin{array}{l}\text { Informational support } \\
\text { (timely receipt of } \\
\text { important information, } \\
\text { possibility to get } \\
\text { advice); }\end{array}$ & 0,15 & 0,19 & $-0,12$ & $-0,09$ & 0,03 & $-0,07$ \\
\hline $\begin{array}{l}\text { Documental support } \\
\text { (assistance with the } \\
\text { visa and migration } \\
\text { control, notification } \\
\text { requesting to prepare } \\
\text { some documents, } \\
\text { diplomas and } \\
\text { certificates delivery } \\
\text { and so on); }\end{array}$ & 0,01 & $-0,01$ & 0,14 & $0,37^{*}$ & 0,01 & 0,21 \\
\hline $\begin{array}{l}\text { Social support } \\
\text { (concessions and } \\
\text { scholarships, material } \\
\text { help); }\end{array}$ & $0,27^{*}$ & 0,11 & 0,15 & 0,07 & 0,55 & $-0,06$ \\
\hline $\begin{array}{l}\text { Cultural and } \\
\text { educational } \\
\text { components of the } \\
\text { program (acquaintance } \\
\text { with cultural heritage, } \\
\text { history, customs and } \\
\text { traditions of the } \\
\text { country) }\end{array}$ & $0,31 *$ & $\mathbf{0 , 3 8}$ & $\mathbf{0 , 3 8}$ & 0,05 & 0,16 & $0,42^{*}$ \\
\hline
\end{tabular}

In the model of organizational utility above-mentioned factors had significant impact on variance explanation as well, $\mathrm{R}^{2}$ varied from 0.3 to 0.75 . Most informative were models for Russia, Tajikistan and Kyrgyzstan (adjusted $\mathrm{R}^{2}$ about 0.75 ).

Meanwhile, their standardized weights were principally different than in the models of personal utility. Thus, for participants from Russia, the most important factors were linguistic assistance $(\beta=0.36)$, information support $(\beta=0.32)$ and cultural-educational program $(\beta=0.22)$. The last factor had the biggest weight in the model of China $(\beta=0.41)$, while other predictors were insignificant. In the Kazakhstan's model organizational utility was determined by possibility to receive social support $(\beta=0.29)$, whereas linguistic assistance and cultural mass activities were only marginally significant. Young participants 
from Tajikistan focused on informational support $(\beta=0.61)$ and cultural program $(\beta=0.29)$, while in the Kyrgyz model organizational utility was associated with obtaining the necessary documentation. It is, therefore, important to underline that the assessment of exchange program efficiency from the individual and organizational points of view was based in different understanding of what was important, that surely reflects peculiarity of reporting requirements in sending organizations, complications or excessive formalities faced by participants. That is why Russian youth was concerned with linguistic assistance, for Tajik young people problems of informational support and effective communication were among most relevant, and for Kyrgyz participants at the crux of the matter were questions related to harmonization of documents and procedures. Ultimately, only representatives of other countries felt free from obligations to their organizations and drew attention to substantive and not organizational aspect of exchange program.

\section{Conclusions}

Participation in exchanges programs gives possibility to develop educational and sociocultural competences (practice of foreign language, ethnocultural competences and so on.) throughout life. Living next to and communicating with people from other countries, the youth acquire appreciated experience of intercultural interaction and international cooperation, rethink own culture and values, learn to take complex decisions considering interests, opinions and needs of all parties. Current processes of international economic, cultural and political integration, namely within the framework of the SCO area, lends new significance to the task of development of innovative potential of international youth cooperation and creation of structures, oriented at involving talented and creative youth in elaboration of collaborative scientific and business projects. The development of youth exchanges is directly linked with necessity for increasing effectiveness of educational and public associations in the field of comprehensive humanitarian cooperation in the SCO countries, youth mobility, contribution to deeper understanding of undergoing socioeconomic, socio-political, technological and cultural transformations in the modern society.

Summarizing the results of the research, it is worth to mention, that short-term exchange programs in the SCO countries are more demanded, they have higher evaluations of satisfaction and quality of preparation and conduct, whereas mid- and long-term programs of academic mobility are rather weak and uncompetitive.

At the top of the list of criteria, by which participants assess the quality of exchange programs are possibilities to achieve goals of personal and sociocultural development, while organizational factors are secondary, estimated on the basis of earlier experience and belonging to demographic and country group. Thus, decreases in valuations were typical for men and more young participants, as well as for those who faced difficulties or was obliged to invest own funds.

Unfortunately, for Russian youth and young people from the SCO countries and far abroad, Russia and the SCO are not considered as credible alternative for international exchange programs of world-class, the youth is still much oriented at receiving experience in western-type programs. Meanwhile, with increasing integration in the Eurasian area the need for intensification of youth exchanges and reorientation of intentions and expectations of youth towards Eurasian values and cultural patterns of conduct will increase and take shape. It is noticeable that further intentions of significant part of young people are linked with Russia: about fifth part of respondents plan to take part in programs there. As far as citizens of China have higher potential of mobility, it is likely that they will form primary target audience of exchange programs with Russia. 
To enhance the effectiveness of international cooperation in the youth field, there is the need to focus not only on improving existing forms of international youth cooperation but also on creating new mechanisms, trends and practices.

\section{Acknowledgments}

Paper is prepared in the framework of the Ministry of Education and Science of the Russian Federation State Order for the scientific research "Transit migration, transit regions and Russian migration policy: security and Eurasian integration” [№ 28.2757.2017/4.6].

\section{References}

1. P. G. Altbach, J. Knight, J. of stud. in international education, 11, pp. 290-305 (2007).

2. R. King, A. Lulle, L. Morosanu, A. Williams, International youth mobility and life transitions in Europe: Questions, definitions, typologies and theoretical approaches (2016).

3. J. S. Nye, The annals of the American academy of political and social science, 616, pp. 94-109 (2008).

4. C. Atkinson, Foreign Policy Analysis, 6, pp. 1-22 (2010).

5. M. Johnson, Higher Education in the Global Age: Policy, Practice and Promise in Emerging Societies, 70 (2013).

6. L. Arefiev, F. E. Sheregi, Foreign Students in Russian Higher Schools (in Russian) (CSR publ., Moscow, 2014).

7. S. G. Maximova (Ed.), Youth exchanges among countries participants of the Shanghai Cooperation Organization (In Russian) (ASU Publishing house, Barnaul, 2015)

8. S. G. Maximova, O. Ye. Noyanzina, D. A. Omelchenko, M. B. Maximov \& G. C. Avdeeva, International journal of environmental \& science education, 11, 11, pp. 4885-4893 (2016)

9. C. Pursiainen, S. Medvedev (Eds.), The Bologna process and its implications for Russia: the European integration of higher education (Russian-European Centre for Economic, 2005).

10. D. M. Hoffman, J. of Studies in Intern. Education, 13, 3, pp. 347-364 (2009).

11. T. Kim, Intercultural education, 20, 5, pp. 395-405 (2009).

12. L. T. Tran, In Reforming learning and teaching in Asia-Pacific universities, pp. 95113 (Springer, Singapore, 2016).

13. I. Gatev, G. Diesen, European Politics and Society, 17 (sup1), pp. 133-150 (2016).

14. R. Alimov, J. of Eurasian studies, 9,2, pp. 114-124 (2018). 